\title{
PENGARUH FOOTBATH TREATMENT TERHADAP NYERI POST SECTIO CAESAREA DI RUANG MELATI RSUD DR SOEKARDJO TASIKMALAYA TAHUN 2019
}

\section{DETTY CHOTIMAH ${ }^{1}$, YULIA HERLIANI ${ }^{2}$, ENDANG ASTIRIYANI ${ }^{3}$}

\author{
1,2,3 Program Studi Diploma IV Kebidanan Poltekkes Kemenkes Tasikmalaya \\ Jl. Cilolohan No 35 Kecamatan Tawang Kota Tasikmalaya \\ e-mail : dettychotimah87@gmail.com
}

DOI : $10.35451 / j k k . v 3 i 1.420$

\begin{abstract}
Sectio caesarea is a surgical procedure in giving birth with an abdominal incision and uterus that have higher morbidity than normal childbirth. Foot bath treatment is one part of post natal spa can release endorphins in the brain which is a natural pain reliever. The purpose of this research is to determine the effect of foot bath treatment on post SC pain in Melati room RSUD dr Soekardjo Tasikmalaya.This research was used pre eksperimental with pretest posttest design. The research instrument used Numerical Rating Scale (NRS). Sampling technique was used purposive sampling with 30 respondents. Foot bath treatment is done for 15 minutes. The analyzed was by Wilcoxon Signed Rank Test. The result of this research showed that the scale of pain before getting foot bath treatment is mostly moderate pain as many as 26 peoples $(87,7 \%)$. The scale of pain after getting foot bath treatment is mostly mild pain as many as 25 peoples $(83,3 \%)$. The result of the statistical test showed $p$ value 0,000 $<0,05$ it means there is an effect of foot bath treatment to post SC pain.
\end{abstract}

Keywords: Post Sectio Caesarea, Pain, Foot bath Treatment

\section{Pendahuluan}

Sectio caesarea adalah suatu tindakan pembedahan dalam melahirkan anak dengan insisi abdomen dan uterus. World Health Organization (WHO) menetapkan standar rata-rata sectio caesarea di sebuah Negara adalah sekitar (5-15\%) per 1000 kelahiran di dunia, Rumah Sakit pemerintah kira - kira (11\%) sementara Rumah Sakit swasta bisa lebih dari (30\%) (Gibbons \& Jose, 2010).
Hasil Riset Kesehatan Dasar (Kemenkes RI, 2013) menunjukan bahwa kejadian persalinan dengan tindakan setio caesarea di Indonesia mencapai $(9,8 \%)$ dari jumlah persalinan, dengan proporsi tertinggi di DKI Jakarta terdapat (19,9\%) dan tindakan setio caesarea terendah terdapat di Sulawesi Tenggara dengan jumlah $(3,3 \%)$, sedangkan di Jawa Barat menunjukan kelahiran dengan sectio caesarea sebesar $(7,8 \%)$ dari jumlah persalinan. Berdasarkan hasil studi 
pendahuluan mengenai data persalinan secara Sectio Caesarea di RSUD dr Soekardjo Tasikmalaya menunjukan bahwa dari bulan Januari-Agustus 2018 terdapat 792 orang melakukan Sectio Caesarea dari 2540 persalinan.

Angka kesakitan ibu pada tindakan Sectio Caesarea lebih tinggi dari pada persalinan normal dan dapat memungkinkan terjadinya komplikasi lebih tinggi daripada persalinan normal. Komplikasi yang bisa timbul pada ibu post sectio caesarea seperti nyeri pada daerah insisi, potensi terjadinya thrombosis, potensi terjadinya penurunan kemampuan fungsional, penurunan elastisitas otot perut dan otot dasar panggul, perdarahan, luka kandung kemih, infeksi, bengkak pada ekstremitas bawah dan gangguan laktasi (Rustam, 2012).

Respon nyeri yang dirasakan oleh pasien merupakan efek samping yang timbul setelah menjalani suatu operasi. Nyeri yang disebabkan oleh operasi biasanya membuat pasien merasa sangat kesakitan.

Penanganan yang sering digunakan untuk menurunkan nyeri post sectio caesarea berupa penanganan farmakologi dan non farmakologi.

Penanganan farmakologi untuk menghilangkan nyeri dengan menggunakan analgesik yang terbagi menjadi dua golongan yaitu analgesik non narkotik dan analgesik narkotik. Penanganan non farmakologi saat ini menjadi trend baru dan merupakan metode alternatif untuk mengurangi nyeri pada ibu post Sectio Caesarea. Menurut Black \& Hawks (2009) penanganan non farmakologi tersebut diantaranya stimulasi kulit, massage, rendam kaki menggunakan air hangat (footbath therapy), akupuntur, akupresur, distraksi, relaksasi dan guided imagery.

Foot bath treatment merupakan salah satu bagian dari rangkaian postnatal spa yang di dalamnya terdiri dari foot bath dan foot massage yang dapat memberikan respon relaksasi, meredakan nyeri tubuh karena dapat membantu dalam pelepasan hormon endorfin di otak yang merupakan pereda nyeri alami.

Hasil studi pendahulan peneliti di Ruang Melati RSUD dr Soekadjo kota Tasikmalaya pada tanggal 8 November 2018, peneliti menemukan 3 orang ibu melahirkan dengan SC merasa nyeri sedang, 1 orang merasa nyeri ringan dan 1 orang tidak merasakan nyeri, untuk mengurangi nyeri, pasien melakukan senam nifas dan mengubah posisi tubuh. Bidan ruangan mengatakan bahwa belum mengetahui foot bath treatment serta belum ada Standar Operasional Prosedur tersebut.

Berdasarkan uraian diatas, maka peneliti merasa tertarik untuk meneliti mengenai pengaruh foot bath treatment terhadap nyeri pada ibu post sectio caesarea di Ruang Melati RSUD dr Soekardjo Kota Tasikmalaya.

\section{METODE}

Jenis penelitian ini adalah pre eksperimental design, rancangan penelitian yang digunakan pada penelitian ini ialah pretest-posttest design. Penelitian ini telah dilaksanakan pada 17 Januari 2019 -1 Februari 2019 di ruang Melati RSUD dr Soekardjo Kota Tasikmalaya. Populasi yang digunakan dalam penelitian ini ialah seluruh pasien post SC di ruang Melati RSUD dr Soekardjo kota Tasikmalaya.

Metode sampling yang digunakan dalam penelitian ini adalah purposive sampling yaitu 30 responden yang memenuhi kriteria inklusi yang sudah ditentukan oleh peneliti. Instrumen penelitian yang digunakan yaitu Standar Opersional Prosedur foot bath treatment dan Numeric Rating Scale untuk mengetahui tingkat nyeri responden sebelum dan sesudah diberikan intervensi di Ruang Melati RSUD dr Soekardjo Tasikmalaya. 
Pengumpulan data menggunakan data primer. Foot bath treatment dilakukan selama 15 menit pada pasien post SC hari kedua, karena pasien tidak mendapatkan analgetik. Sebelum dilakukan intervensi, responden diberikan penjelasan mengenai kegiatan yang akan dilakukan dan menandatangani lembar informed consent. Sebelum dilakukan intervensi, responden diminta untuk mengungkapkan rasa nyeri dengan mengisi skala nyeri Numeric Rating Scale (NRS). Setelah dilakukan intervensi, responden diminta untuk mengungkapkan rasa nyerinya kembali menggunakan skala nyeri Numeric Rating Scale (NRS).

Analisa univariat dalam penelitian ini menggunakan distribusi frekuensi dengan hasil presentasi yang didapatkan dari nilai pretest dan posttest. Analisa bivariat yang digunakan yaitu Uji Wilcoxon Signed Rank Test.

\section{HASIL}

Tabel 1. Distribusi Frekuensi Tingkat Nyeri Ibu Post Sectio Caesarea sebelum diberikan footbath treatment di RSUD dr

Soekardjo Tasikmalaya Tahun 2019

\begin{tabular}{lcc}
\hline \multicolumn{1}{c}{ Kategori } & $\mathrm{F}$ & $\%$ \\
\hline 0 (Tidak Nyeri) & 0 & 0 \\
1-3 (Nyeri ringan) & 2 & 6,7 \\
4-6 (Nyeri Sedang) & 26 & 86,7 \\
7-10 (Nyeri Berat) & 2 & 6,7 \\
\hline \multicolumn{1}{c}{ Jumlah } & 30 & 100
\end{tabular}

Tabel 1 menunjukan bahwa tingkat nyeri pada ibu post Sectio Caesarea sebelum diberikan footbath treatment sebagian besar ada pada kategori nyeri sedang yaitu sebanyak 26 orang $(86,7 \%)$.

Tabel 2. Distribusi Frekuensi Tingkat Nyeri Ibu Post Sectio Caesarea setelah diberikan footbath treatment di RSUD dr Soekardjo Tasikmalaya Tahun 2019

\begin{tabular}{ccc}
\hline Kategori & $\mathrm{F}$ & $\%$ \\
\hline $0 \quad$ (Tidak Nyeri) & 2 & 6,7 \\
$1-3$ (Nyeri ringan) & 25 & 83,3 \\
4-6 (NyeriSedang) & 3 & 10 \\
7-10 (Nyeri Berat) & 0 & 0 \\
\hline Jumlah & 30 & 100 \\
\hline
\end{tabular}

Tabel 2 menunjukan bahwa tingkat nyeri pada ibu post Sectio Caesarea setelah diberikan footbath treatment sebagian besar ada pada kategori nyeri ringan yaitu sebanyak 25 orang $(83,3 \%)$.

Tabel 3 Ranking Frekuensi Nyeri Post Sectio Caesarea setelah dilakukan Foot bath treatment di Ruang Melati RSUD dr

Soekardjo Tasikmalaya Tahun 2019

\begin{tabular}{ccc}
\hline $\begin{array}{c}\text { Setelah Foot bath } \\
\text { treatment }\end{array}$ & $\mathrm{N}$ & $\begin{array}{c}\text { Ranking } \\
\text { rata-rata }\end{array}$ \\
\hline Ranking Negatif & 28 & 14,50 \\
Ranking Positif & 0 &, 00 \\
Tetap & 2 & \\
\hline Jumlah & 30 & \\
\hline
\end{tabular}

Berdasarkan Tabel 3 hasil uji Wilcoxon menunjukan bahwa setelah dilakukan foot bath treatment 28 orang mengalami penurunan rasa nyeri dengan ranking rata-rata 14,50 dan 2 orang tidak mengalami penurunan nyeri (tetap).

Tabel 4 Pengaruh footbath treatment terhadap nyeri post Sectio Caesarea di ruang Melati RSUD dr Soekardjo Tasikmalaya Tahun 2019

\begin{tabular}{lcccc}
\hline \multicolumn{1}{c}{ Nyeri } & N & $\%$ & Z & Sig \\
\hline Sebelum & & & & \\
Tidak nyeri & 0 & 0 & & \\
Ringan & 2 & 6,7 & & \\
Sedang & 26 & 86,7 & & \\
Berat & 2 & 6,7 & & \\
& & & $-4,663$ & 0,000 \\
Setelah & & & & \\
Tidak nyeri & 2 & 6,7 & & \\
Ringan & 25 & 83,3 & & \\
Sedang & 3 & 10 & & \\
Berat & 0 & 0 & & \\
\hline
\end{tabular}

Berdasarkan tabel 4 hasil uji Wilcoxon menunjukan bahwa $Z$ sebesar $-4,663$ dengan signifikansi sebesar 0,000. Hal ini menunjukan bahwa kolerasi antara dua variabel rata-rata sebelum dan sesudah adalah kuat dan signifikan. Berdasarkan uji Wilcoxon didapatkan nilai pValue sebesar 0,000 dan karena pValue 0,000 < a $(0,05)$ maka $\mathrm{H}_{0}$ ditolak, yang berarti bahwa ada pengaruh footbath treatment terhadap nyeri post Sectio Caesarea di ruang Melati RSUD dr Soekardjo Tasikmalaya. 


\section{PEMBAHASAN}

Berdasarkan hasil penelitian yang telah dideskripsikan diatas diperoleh bahwa gambaran nyeri pada ibu post Sectio Caesarea sebelum mendapatkan perlakuan foot bath treatment di ruang Melati RSUD dr Soekardjo Tasikmalaya sebagian besar mengalami nyeri sedang sebanyak 26 orang $(86,7 \%)$. Penelitian ini sejalan dengan Wahyuni (2016) bahwa sebelum pemberian terapi rendam kaki air hangat sebagian responden mengalami nyeri sedang yaitu 11 orang $(73,3 \%)$.

Nyeri yang dirasakan ibu post Sectio Caesarea berasal dari luka yang terdapat dari perut. Tindakan operasi menyebabkan terjadinya perubahan kontinuitas jaringan tubuh, pada proses operasi digunakan anastesi agar pasien tidak merasakan nyeri, namun setelah operasi selesai dan pasien mulai sadar maka pasien akan merasakan nyeri pada bagian tubuh yang mengalami pembedahan (Patasik dkk, 2013).

Tingkat nyeri pada pasien post SC setelah mendapatkan foot bath treatment sebagian besar mengalami rasa nyeri ringan sebanyak 25 orang $(83,7 \%)$. Hasil penelitian ini sejalan dengan Wahyuni (2016) bahwa setelah pemberian terapi rendam kaki air hangat sebagian besar dari responden mengalami nyeri ringan yaitu 13 responden $(86,7 \%)$.

Perubahan nyeri sebelum dan setelah diberikan foot bath treatment pada masing-masing sampel berbeda, perubahan nyeri dapat dipengaruhi oleh beberapa faktor diantaranya usia, kebudayaan, makna nyeri, perhatian, kecemasan, dukungan keluarga.

Foot bath treatment dilakukan pada pasien post Sectio Caesarea hari kedua karena berdasarkan hasil studi pendahuluan dengan cara wawancara kepada bidan ruangan bahwa pada hari kedua ibu post Sectio Caesarea sudah bisa beradaptasi, melakukan mobilisasi, duduk dan pasien tidak diberikan anti nyeri. Anti nyeri hanya diberikan pada 24 jam pertama setelah dilakukannya Sectio Caesarea dan pada hari ketiga. Berdasarkan hasil wawancara dengan pasien, untuk mengurangi nyeri biasanya pasien melakukan senam nifas dan mengubah posisi tubuh.

Berdasarkan hasil uji Wilcoxon dengan tingkat kepercayaan 95\% atau $a=0,05$ menunjukan bahwa setelah dilakukan foot bath treatment terdapat 28 responden mengalami penurunan rasa nyeri dengan ranking rata-rata $(14,50), 2$ responden tidak mengalami penurunan nyeri (tetap), dan tidak ada responden yang mengalami kenaikan rasa nyeri.

Hal ini disebabkan karena nyeri merupakan pengalaman personal, subyektif dan tidak ada dua individu yang mengalami kesamaan rasa nyeri dan respon yang sama pada individu, selain itu perubahan nyeri dapat juga oleh usia, jenis kelamin, kebudayaan, makna nyeri, perhatian dan kecemasan (Muttaqin, 2008).

Nilai $p$ value dari hasil uji Wilcoxon adalah $0,000 \quad(p<0,05)$ yang berarti menunjukan bahwa ada pengaruh footbath treatment terhadap nyeri post Sectio Caesarea di ruang Melati RSUD dr Soekardjo Tasikmalaya.

Foot bath treatment dilakukan dengan cara merendam kaki menggunakan air hangat yang bersuhu $38^{\circ} \mathrm{C}$ sampai $40^{\circ} \mathrm{C}$ dan garam aromaterapi yang disertai dengan pijatan pada kaki. Pada suhu $38^{\circ} \mathrm{C}$ sampai $40^{\circ} \mathrm{C}$ akan terjadi efek thermal yaitu efek panas yang dapat meningkatkan sirkulasi darah dan penyerapan oksigen ke dalam tubuh (Lalage, 2015). Air hangat bila menempel pada jaringan kulit akan terjadi vasodilatasi (pelebaran pembuluh darah) sehingga dapat memimbulkan respon relaksasi (Meiliya \& Wahyuningsih, 2010).

Garam aroma terapi atau garam spa adalah suatu aroma atau terapi berbentuk garam yang didalamnya terdapat banyak mineral yaitu natrium, magnesium, 
kalsium, bromida. Garam aroma terapi membantu memperlancar peredaran darah (Meiliya \& Wahyuningsih, 2010)

Foot massage (pijatan pada kaki) merupakan pijatan lembut pada punggung kaki hingga betis. Pijat ini dilakukan pada menit ke 11 sampai menit ke 15 saat intervensi foot bath treatment. Respon relaksasi akan memicu keluarnya hormon endorfin yaitu zat kimia seperti morfin yang diproduksi sendiri oleh tubuh yang fungsi utamanya untuk menumpulkan rasa nyeri, selain itu hormon endorfin juga dapat memicu perasaan senang, tenang dan bahagia.

\section{KESIMPULAN}

a. Gambaran nyeri ibu post Sectio Caesarea sebelum diberikan footbath treatment sebagian besar termasuk kategori nyeri sedang dengan jumlah 26 orang $(86,7 \%)$.

b. Gambaran nyeri ibu post Sectio Caesarea setelah diberikan footbath treatment sebagian besar termasuk kategori nyeri ringan dengan jumlah 25 orang $(83,3 \%)$.

c. Terdapat pengaruh foot bath treatment terhadap nyeri post Sectio caesarea di Ruang Melati RSUD dr Soekardjo Kota Tasikmalaya dengan nilai $p$-value $0,000(<0,05)$ artinya terdapat pengaruh foot bath treatment terhadap penurunan nyeri post Sectio caesarea.

\section{DAFTAR PUSTAKA}

Black, J \& Hawks, J, (2009), Keperawatan Medikal Bedah: Manajemen Klinis untuk Hasil yang diharapkan. Dialih bahasakan oleh Nampira $R$, Salemba Emban Patria, Jakarta.

Gibbons, L \& Jose, (2010), The Global Numbers and Costs of Additionally Needed and Unne Cessary Caesarean Sections Performed per Year:Overase as a Barter to Universal Coverage, World Health Report, Diperoleh dari https://www.who.int/healthsystems/ topics/financing/healthreport/30C- sectioncosts.pdf diakses pada tanggal 14 November 2018.

Kemenkes RI, (2013), Riset Kesehatan Dasar: RISKESDAS, Balitbang, Jakarta.

Lalage, Z, (2015), Hidup Sehat dengan Terapi Air, Abata Press, Yogyakarta.

Meiliya, E \& Wahyuningsih, (2010), Buku Saku Kebidanan, EGC, Jakarta.

Muttaqin, A, (2008), Buku Ajar Asuhan Keperawatan Klien dengan Gangguan Sistem Persarafan, Salemba Medika, Jakarta.

Patasik dkk, (2013), Efektifitas Teknik Relaksasi Nafas Dalam dan Guided Imagery Terhadap Penurunan Nyeri pada Pasien Post Operasi Sectio Caesarea di Irina D Blu RSUP Prof. Dr. R. D. Kandou Manado, Diperoleh dari https://ejournal.unsrat.ac.id/index.p $\mathrm{hp} / \mathrm{jkp} / \mathrm{article} / \mathrm{view} / 2169$ diakses pada tanggal 13 Februari 2019.

Rustam, M, (2012), Sinopsis Obstetri: Obstetri Fisiologi, Obstetri Patologi, EGC, Jakarta.

Wahyuni, C, (2016), Pengaruh Pemberian Terapi Rendam Air Hangat Terhadap Nyeri Kram Kaki pada Ibu Hamil Trimester II dan III, Diperoleh dari https://adoc.tips/peningkatankesehatan-di-negara-tropis-melaluione-health-si.html diakses pada tanggal 27 Februari 2019. 